\title{
Further fixed point results on $G$-metric spaces
}

\author{
Erdal Karapınar ${ }^{1 *}$ and Ravi P Agarwal ${ }^{2,3}$
}

"Correspondence:
erdalkarapinar@yahoo.com;
ekarapinar@atilim.edu.tr
'Department of Mathematics,
Atilim University, İncek, Ankara
06836, Turkey
Full list of author information is
available at the end of the article

available at the end of the article

\section{Springer}

\begin{abstract}
Very recently, Samet et al. (Int. J. Anal. 2013:917158, 2013) and Jleli-Samet (Fixed Point Theory Appl. 2012:210, 2012) noticed that some fixed point theorems in the context of a G-metric space can be deduced by some well-known results in the literature in the setting of a usual (quasi) metric space. In this paper, we note that the approach of Samet et al. (Int. J. Anal. 2013:917158, 2013) and Jleli-Samet (Fixed Point Theory Appl. 2012:210, 2012) is inapplicable unless the contraction condition in the statement of the theorem can be reduced into two variables. For this purpose, we modify some existing results to suggest new fixed point theorems that fit with the nature of a $G$-metric space. The expressions in our result, the contraction condition, cannot be expressed in two variables, therefore the techniques used in (Int. J. Anal. 2013:917158, 2013; Fixed Point Theory Appl. 2012:210, 2012) are not applicable.

MSC: $47 \mathrm{H} 10 ; 54 \mathrm{H} 25$
\end{abstract}

Keywords: coupled fixed point; fixed point; ordered set; metric space

\section{Introduction}

The concept of G-metric space was introduced by Mustafa and Sims [1] in order to extend and generalize the notion of metric space. In this paper, the authors characterized the Banach contraction mapping principle [2] in the context of a G-metric space. Following this initial report, a number of authors have characterized many well-known fixed point theorems in the setting of $G$-metric space (see, e.g., $[1,3-36]$ ). Since one is adapted from the other, there is a close relation between a usual metric space and a $G$-metric space (see, e.g., $[1,23-27])$. In fact, the nature of a G-metric space is to understand the geometry of three points instead of two points via perimeter of a triangle. However, most of the published papers dealing with a G-metric space did not give much importance to these details. Consequently, a great majority of results were obtained by transforming the contraction conditions from the usual metric space context to a $G$-metric space without carrying enough of the characteristics of the $G$-metric.

Very recently, Samet et al. [37] and Jleli-Samet [38] observed that some fixed point theorems in the context of a $G$-metric space in the literature can be concluded by some existing results in the setting of a (quasi-)metric space. In fact, if the contraction condition of the fixed point theorem on a $G$-metric space can be reduced to two variables instead of three variables, then one can construct an equivalent fixed point theorem in the setup of a usual metric space. More precisely, in [37, 38], the authors noticed that $d(x, y)=G(x, y, y)$ forms a quasi-metric. Hence, if one can transform the contraction condition of existence results in a $G$-metric space in such terms, $G(x, y, y)$, then the related fixed point results become the known fixed point results in the context of a quasi-metric space.

(c) 2013 Karapınar and Agarwal; licensee Springer. This is an Open Access article distributed under the terms of the Creative Commons Attribution License (http://creativecommons.org/licenses/by/2.0), which permits unrestricted use, distribution, and reproduction in any medium, provided the original work is properly cited. 
In this paper, we notice that the techniques used in $[37,38]$ are valid if the contraction condition in the statement of the theorem can be expressed in two variables. Furthermore, we prove some fixed point theorems in the context of a $G$-metric space for which the techniques in $[37,38]$ are inapplicable.

\section{Preliminaries}

In this section we recollect basic definitions and a detailed overview of the fundamental results. Throughout this paper, $\mathbb{N}$ is the set of nonnegative integers, and $\mathbb{N}^{*}$ is the set of positive integers.

Definition 2.1 (See [1]) Let $X$ be a non-empty set and let $G: X \times X \times X \rightarrow \mathbb{R}^{+}$be a function satisfying the following properties:

(G1) $G(x, y, z)=0$ if $x=y=z$,

(G2) $0<G(x, x, y)$ for all $x, y \in X$ with $x \neq y$,

(G3) $G(x, x, y) \leq G(x, y, z)$ for all $x, y, z \in X$ with $y \neq z$,

(G4) $G(x, y, z)=G(x, z, y)=G(y, z, x)=\cdots$ (symmetry in all three variables),

(G5) $G(x, y, z) \leq G(x, a, a)+G(a, y, z)$ for all $x, y, z, a \in X$ (rectangle inequality).

Then the function $G$ is called a generalized metric or, more specifically, a $G$-metric on $X$, and the pair $(X, G)$ is called a $G$-metric space.

Every $G$-metric on $X$ defines a metric $d_{G}$ on $X$ by

$$
d_{G}(x, y)=G(x, y, y)+G(y, x, x) \quad \text { for all } x, y \in X .
$$

Example 2.1 Let $(X, d)$ be a metric space. The function $G: X \times X \times X \rightarrow[0,+\infty)$, defined as

$$
G(x, y, z)=\max \{d(x, y), d(y, z), d(z, x)\}
$$

or

$$
G(x, y, z)=d(x, y)+d(y, z)+d(z, x)
$$

for all $x, y, z \in X$, is a $G$-metric on $X$.

Definition 2.2 (See [1]) Let $(X, G)$ be a $G$-metric space, and let $\left\{x_{n}\right\}$ be a sequence of points of $X$. We say that $\left\{x_{n}\right\}$ is $G$-convergent to $x \in X$ if

$$
\lim _{n, m \rightarrow+\infty} G\left(x, x_{n}, x_{m}\right)=0,
$$

that is, for any $\varepsilon>0$, there exists $N \in \mathbb{N}$ such that $G\left(x, x_{n}, x_{m}\right)<\varepsilon$ for all $n, m \geq N$. We call $x$ the limit of the sequence and write $x_{n} \rightarrow x$ or $\lim _{n \rightarrow+\infty} x_{n}=x$.

Proposition 2.1 (See [1]) Let $(X, G)$ be a G-metric space. The following are equivalent:

(1) $\left\{x_{n}\right\}$ is G-convergent to $x$,

(2) $G\left(x_{n}, x_{n}, x\right) \rightarrow 0$ as $n \rightarrow+\infty$, 
(3) $G\left(x_{n}, x, x\right) \rightarrow 0$ as $n \rightarrow+\infty$,

(4) $G\left(x_{n}, x_{m}, x\right) \rightarrow 0$ as $n, m \rightarrow+\infty$.

Definition 2.3 (See [1]) Let $(X, G)$ be a $G$-metric space. A sequence $\left\{x_{n}\right\}$ is called a G-Cauchy sequence if, for any $\varepsilon>0$, there is $N \in \mathbb{N}$ such that $G\left(x_{n}, x_{m}, x_{l}\right)<\varepsilon$ for all $m, n, l \geq N$, that is, $G\left(x_{n}, x_{m}, x_{l}\right) \rightarrow 0$ as $n, m, l \rightarrow+\infty$.

Proposition 2.2 (See [1]) Let $(X, G)$ be a G-metric space. Then the following are equivalent:

(1) the sequence $\left\{x_{n}\right\}$ is G-Cauchy,

(2) for any $\varepsilon>0$, there exists $N \in \mathbb{N}$ such that $G\left(x_{n}, x_{m}, x_{m}\right)<\varepsilon$ for all $m, n \geq N$.

Definition 2.4 (See [1]) A G-metric space $(X, G)$ is called $G$-complete if every $G$-Cauchy sequence is $G$-convergent in $(X, G)$.

We will use the following result which can be easily derived from the definition of a G-metric space (see, e.g., [1]).

Lemma 2.1 Let $(X, G)$ be a G-metric space. Then

$$
G(x, x, y) \leq 2 G(x, y, y) \quad \text { for all } x, y \in X \text {. }
$$

Definition 2.5 (See [1]) Let $(X, G)$ be a $G$-metric space. A mapping $T: X \rightarrow X$ is said to be $G$-continuous if $\left\{T\left(x_{n}\right)\right\}$ is $G$-convergent to $T(x)$ where $\left\{x_{n}\right\}$ is any $G$-convergent sequence converging to $x$.

In [22], Mustafa characterized the well-known Banach contraction mapping principle in the context of $G$-metric spaces in the following ways.

Theorem 2.1 (See [22]) Let $(X, G)$ be a complete G-metric space and let $T: X \rightarrow X$ be a mapping satisfying the following condition for all $x, y, z \in X$ :

$$
G(T x, T y, T z) \leq k G(x, y, z)
$$

where $k \in[0,1)$. Then $T$ has a unique fixed point.

Theorem 2.2 (See [22]) Let $(X, G)$ be a complete G-metric space and let $T: X \rightarrow X$ be a mapping satisfying the following condition for all $x, y \in X$ :

$$
G(T x, T y, T y) \leq k G(x, y, y)
$$

where $k \in[0,1)$. Then $T$ has a unique fixed point.

Remark 2.1 The condition (2) implies the condition (3). The converse is true only if $k \in$ $\left[0, \frac{1}{2}\right)$. For details, see [22]. 
Theorem 2.3 (See [26]) Let $(X, G)$ be a G-metric space. Let $T: X \rightarrow X$ be a mapping such that

$$
G(T x, T y, T z) \leq a G(x, y, z)+b G(x, T x, T x)+c G(y, T y, T y)+d G(z, T z, T z)
$$

for all $x, y, z$, where $a, b, c, d$ are positive constants such that $k=a+b+c+d<1$. Then there is a unique $x \in X$ such that $T x=x$.

Theorem 2.4 (See [27]) Let $(X, G)$ be a G-metric space. Let $T: X \rightarrow X$ be a mapping such that

$$
G(T x, T y, T z) \leq k[G(x, T x, T x)+G(y, T y, T y)+G(z, T z, T z)]
$$

for all $x, y, z$, where $k \in\left[0, \frac{1}{3}\right)$. Then there is a unique $x \in X$ such that $T x=x$.

Theorem 2.5 (See [26]) Let $(X, G)$ be a G-metric space. Let $T: X \rightarrow X$ be a mapping such that

$$
G(T x, T y, T z) \leq a G(x, y, z)+b[G(x, T x, T x)+G(y, T y, T y)+G(z, T z, T z)]
$$

for all $x, y, z$, where $a, b$ are positive constants such that $k=a+b<1$. Then there is a unique $x \in X$ such that $T x=x$.

Theorem 2.6 (See [26]) Let $(X, G)$ be a G-metric space. Let $T: X \rightarrow X$ be a mapping such that

$$
G(T x, T y, T z) \leq a G(x, y, z)+b \max \{G(x, T x, T x), G(y, T y, T y), G(z, T z, T z)\}
$$

for all $x, y, z$, where $a, b$ are positive constants such that $k=a+b<1$. Then there is a unique $x \in X$ such that $T x=x$.

Theorem 2.7 (See [25]) Let $(X, G)$ be a G-metric space. Let $T: X \rightarrow X$ be a mapping such that

$$
\begin{aligned}
G(T x, T y, T z) \leq & k \max \{G(x, y, z), G(x, T x, T x), G(y, T y, T y), G(z, T z, T z) \\
& G(z, T x, T x), G(x, T y, T y), G(y, T z, T z)\}
\end{aligned}
$$

for all $x, y, z$, where $k \in\left[0, \frac{1}{2}\right)$. Then there is a unique $x \in X$ such that $T x=x$.

Theorem 2.8 (See, e.g., [38]) Let $(X, G)$ be a complete G-metric space and let $T: X \rightarrow X$ be a given mapping satisfying

$$
G(T x, T y, T z) \leq G(x, y, z)-\varphi(G(x, y, z))
$$

for all $x, y \in X$, where $\varphi:[0, \infty) \rightarrow[0, \infty)$ is continuous with $\varphi^{-1}(\{0\})=0$. Then there is a unique $x \in X$ such that $T x=x$. 
Definition 2.6 (See, e.g., [38]) A quasi-metric on a nonempty set $X$ is a mapping $p: X \times$ $X \rightarrow[0, \infty)$ such that

$\left(\mathrm{p}_{1}\right) x=y$ if and only if $p(x, y)=0$,

$\left(\mathrm{p}_{2}\right) p(x, y) \leq p(x, z)+p(z, y)$,

for all $x, y, z \in X$. A pair $(X, p)$ is said to be a quasi-metric space.

Samet et al. [37] and Jleli-Samet [38] noticed that $p(x, y)=p_{G}(x, y)=G(x, y, y)$ is a quasimetric whenever $G: X \times X \times X \rightarrow[0, \infty)$ is a $G$-metric. It is well known that each quasimetric induces a metric. Indeed, if $(X, p)$ is a quasi-metric space, then the function defined by

$$
d(x, y)=d_{G}(x, y)=\max \{p(x, y), p(y, x)\} \quad \text { for all } x, y \in X
$$

is a metric on $X$.

Theorem 2.9 Let $(X d)$ be a complete metric space and let $T: X \rightarrow X$ be a mapping with the property

$$
d(T x, T y) \leq q \max \{d(x, y), d(x, T x), d(y, T y), d(x, T y), d(y, T x)\}
$$

for all $x \in X$, where $q$ is a constant such that $q \in[0,1)$. Then $T$ has a unique fixed point.

Samet et al. [37] proved that Theorem 2.4-Theorem 2.7 are the consequences of Theorem 2.9 by using the following proposition.

\section{Proposition 2.3}

(A) If $(X, G)$ is a complete $G$-metric space, then $(X, d)$ is a complete metric space.

(B) If $(X, G)$ is a sequentially G-compact $G$-metric space, then $(X, d)$ is a compact metric space.

\section{Main results}

We first state the following theorem about the existence and uniqueness of a common fixed point, which is a generalization of Theorem 2.7. Furthermore, the techniques of the papers $[37,38]$ are not applicable to this theorem.

Theorem 3.1 Let $(X, G)$ be a G-metric space. Let $T: X \rightarrow X$ be a mapping such that

$$
G(T x, T y, T z) \leq k M(x, y, z)
$$

for all $x, y, z$, where $k \in\left[0, \frac{1}{2}\right)$ and

$$
\begin{aligned}
M(x, y, z)= & \max \left\{G(x, T x, y), G\left(y, T^{2} x, T y\right), G\left(T x, T^{2} x, T y\right), G(y, T x, T y), G(x, T x, z),\right. \\
& G\left(z, T^{2} x, T z\right), G\left(T x, T^{2} x, T z\right), G(z, T x, T y), G(x, y, z), G(x, T x, T x), \\
& G(y, T y, T y), G(z, T z, T z), G(z, T x, T x), G(x, T y, T y), G(y, T z, T z)\} .
\end{aligned}
$$

Then there is a unique $x \in X$ such that $T x=x$. 
Proof Let $x_{0} \in X$. We define a sequence $\left\{x_{n}\right\}$ in the following way:

$$
x_{n+1}=T x_{n}, \quad n \in \mathbb{N} .
$$

Taking $x=x_{n}, z=y=x_{n+1}$ in (11), we find

$$
G\left(T x_{n}, T x_{n+1}, T x_{n+1}\right) \leq k M\left(x_{n}, x_{n+1}, x_{n+1}\right),
$$

where

$$
\begin{aligned}
M\left(x_{n}, x_{n+1}, x_{n+1}\right)= & \max \left\{G\left(x_{n}, T x_{n}, x_{n+1}\right), G\left(x_{n+1}, T^{2} x_{n}, T x_{n+1}\right), G\left(T x_{n}, T^{2} x_{n}, T x_{n+1}\right),\right. \\
& G\left(x_{n+1}, T x_{n}, T x_{n+1}\right), G\left(x_{n}, T x_{n}, x_{n+1}\right), G\left(x_{n+1}, T^{2} x_{n}, T x_{n+1}\right), \\
& G\left(T x_{n}, T^{2} x_{n}, T x_{n+1}\right), G\left(x_{n+1}, T x_{n}, T x_{n+1}\right), G\left(x_{n}, x_{n+1}, x_{n+1}\right), \\
& G\left(x_{n}, T x_{n}, T x_{n}\right), G\left(x_{n+1}, T x_{n+1}, T x_{n+1}\right), G\left(x_{n+1}, T x_{n+1}, T x_{n+1}\right), \\
& \left.G\left(x_{n+1}, T x_{n}, T x_{n}\right), G\left(x_{n}, T x_{n+1}, T x_{n+1}\right), G\left(x_{n+1}, T x_{n+1}, T x_{n+1}\right)\right\} \\
= & \max \left\{G\left(x_{n}, x_{n+1}, x_{n+1}\right), G\left(x_{n+1}, x_{n+2}, x_{n+2}\right), G\left(x_{n+1}, x_{n+2}, x_{n+2}\right),\right. \\
& G\left(x_{n+1}, x_{n+1}, x_{n+2}\right), G\left(x_{n}, x_{n+1}, x_{n+1}\right), G\left(x_{n+1}, x_{n+2}, x_{n+2}\right), \\
& G\left(x_{n+1}, x_{n+2}, x_{n+2}\right), G\left(x_{n+1}, x_{n+1}, x_{n+2}\right), G\left(x_{n}, x_{n+1}, x_{n+1}\right), \\
& G\left(x_{n}, x_{n+1}, x_{n+1}\right), G\left(x_{n+1}, x_{n+2}, x_{n+2}\right), G\left(x_{n+1}, x_{n+2}, x_{n+2}\right), \\
& \left.G\left(x_{n+1}, x_{n+1}, x_{n+1}\right), G\left(x_{n}, x_{n+2}, x_{n+2}\right), G\left(x_{n+1}, x_{n+2}, x_{n+2}\right)\right\} \\
= & \max \left\{G\left(x_{n}, x_{n+1}, x_{n+1}\right), G\left(x_{n+1}, x_{n+2}, x_{n+2}\right),\right. \\
& \left.G\left(x_{n+1}, x_{n+1}, x_{n+2}\right), G\left(x_{n}, x_{n+2}, x_{n+2}\right)\right\} .
\end{aligned}
$$

Now, we have to examine four cases in (14). For the first case, assume that $M\left(x_{n}, x_{n+1}\right.$, $\left.x_{n+1}\right)=G\left(x_{n+1}, x_{n+2}, x_{n+2}\right)$. Then the expression (13) turns into

$$
\begin{aligned}
G\left(x_{n+1}, x_{n+2}, x_{n+2}\right) & =G\left(T x_{n}, T x_{n+1}, T x_{n+1}\right) \\
& \leq k M\left(x_{n}, x_{n+1}, x_{n+1}\right) \\
& =k G\left(x_{n+1}, x_{n+2}, x_{n+2}\right) .
\end{aligned}
$$

It is a contradiction since $0 \leq k<\frac{1}{2}$. For the second case, assume that $M\left(x_{n}, x_{n+1}, x_{n+1}\right)=$ $G\left(x_{n+1}, x_{n+1}, x_{n+2}\right)$. Regarding (G5) together with the inequality (13), we derive that

$$
\begin{aligned}
G\left(x_{n+1}, x_{n+2}, x_{n+2}\right) & =G\left(T x_{n}, T x_{n+1}, T x_{n+1}\right) \\
& \leq k G\left(x_{n+1}, x_{n+1}, x_{n+2}\right) \\
& \leq k\left[G\left(x_{n+1}, x_{n+2}, x_{n+2}\right)+G\left(x_{n+2}, x_{n+1}, x_{n+2}\right)\right],
\end{aligned}
$$

a contradiction since $0 \leq k<\frac{1}{2}$. 
For the third case, assume that $M\left(x_{n}, x_{n+1}, x_{n+1}\right)=G\left(x_{n}, x_{n+2}, x_{n+2}\right)$. By (G5) and the inequality (13), we have

$$
\begin{aligned}
G\left(x_{n+1}, x_{n+2}, x_{n+2}\right) & =G\left(T x_{n}, T x_{n+1}, T x_{n+1}\right) \\
& \leq k G\left(x_{n}, x_{n+2}, x_{n+2}\right) \\
& \leq k\left[G\left(x_{n}, x_{n+1}, x_{n+1}\right)+G\left(x_{n+1}, x_{n+2}, x_{n+2}\right)\right],
\end{aligned}
$$

which is equivalent to

$$
G\left(x_{n+1}, x_{n+2}, x_{n+2}\right) \leq h G\left(x_{n}, x_{n+1}, x_{n+1}\right),
$$

where $h=\frac{k}{1-k}<1$ since $0 \leq k<\frac{1}{2}$.

For the last case, assume that $M\left(x_{n}, x_{n+1}, x_{n+1}\right)=G\left(x_{n}, x_{n+1}, x_{n+1}\right)$. Then the inequality (13) turns into

$$
G\left(x_{n+1}, x_{n+2}, x_{n+2}\right) \leq k G\left(x_{n}, x_{n+1}, x_{n+1}\right),
$$

where $0 \leq k<\frac{1}{2}$.

As a result, from (15)-(19) we conclude that

$$
G\left(x_{n+2}, x_{n+2}, x_{n+1}\right) \leq r^{n+1} G\left(x_{1}, x_{1}, x_{0}\right),
$$

where $r \in\{h, k\}$ and hence $r<1$. We show that the sequence $\left\{x_{n}\right\}$ is $G$-Cauchy. By the rectangle inequality (G5), we have for $m>n$

$$
\begin{aligned}
G\left(x_{m}, x_{m}, x_{n}\right) \leq & G\left(x_{n+1}, x_{n+1}, x_{n}\right)+G\left(x_{n+2}, x_{n+2}, x_{n+1}\right) \\
& +\cdots+G\left(x_{m-1}, x_{m-1}, x_{m-2}\right)+G\left(x_{m}, x_{m}, x_{m-1}\right) \\
\leq & r^{n} G\left(x_{1}, x_{1}, x_{0}\right)+r^{n+1} G\left(x_{1}, x_{1}, x_{0}\right) \\
& +\cdots+r^{m-2} G\left(x_{1}, x_{1}, x_{0}\right)+r^{m-1} G\left(x_{1}, x_{1}, x_{0}\right) \\
\leq & \left(\sum_{i=n}^{m-1} r^{i}\right) G\left(x_{1}, x_{1}, x_{0}\right) .
\end{aligned}
$$

Letting $n, m \rightarrow \infty$ in (21), we get that $G\left(x_{m}, x_{m}, x_{n}\right) \rightarrow 0$. Hence, $\left\{x_{n}\right\}$ is a $G$-Cauchy sequence in $X$. Since $(X, G)$ is $G$-complete, then there exists $x^{*} \in X$ such that $\left\{x_{n}\right\}$ is $G$ convergent to $x^{*}$. We shall show that $x^{*}=T x^{*}$. Suppose, on the contrary, that $x^{*} \neq T x^{*}$. On the other hand, we have $x_{n+1}=T x_{n}$ and hence

$$
\begin{aligned}
G\left(x_{n+1}, T x^{*}, T x^{*}\right) & =G\left(T x_{n}, T x^{*}, T x^{*}\right) \\
& \leq k M\left(x_{n}, x^{*}, x^{*}\right),
\end{aligned}
$$


where

$$
\begin{aligned}
M\left(x_{n}, x^{*}, x^{*}\right)= & \max \left\{G\left(x_{n}, T x_{n}, x^{*}\right), G\left(x^{*}, T^{2} x_{n}, T x^{*}\right), G\left(T x_{n}, T^{2} x_{n}, T x^{*}\right),\right. \\
& G\left(x^{*}, T x_{n}, T x^{*}\right), G\left(x_{n}, T x_{n}, x^{*}\right), G\left(x^{*}, T^{2} x_{n}, T x^{*}\right), \\
& G\left(T x_{n}, T^{2} x_{n}, T x^{*}\right), G\left(x^{*}, T x_{n}, T x^{*}\right), G\left(x_{n}, x^{*}, x^{*}\right), \\
& G\left(x_{n}, T x_{n}, T x_{n}\right), G\left(x^{*}, T x^{*}, T x^{*}\right), G\left(x^{*}, T x^{*}, T x^{*}\right), \\
& \left.G\left(x^{*}, T x_{n}, T x_{n}\right), G\left(x_{n}, T x^{*}, T x^{*}\right), G\left(x^{*}, T x^{*}, T x^{*}\right)\right\} \\
= & \max \left\{G\left(x_{n}, x_{n+1}, x^{*}\right), G\left(x^{*}, x_{n+2}, T x^{*}\right), G\left(x_{n+1}, x_{n+2}, T x^{*}\right),\right. \\
& G\left(x^{*}, x_{n+1}, T x^{*}\right), G\left(x_{n}, x_{n+1}, x^{*}\right), G\left(x^{*}, x_{n+2}, T x^{*}\right), \\
& G\left(x_{n+1}, x_{n+2}, T x^{*}\right), G\left(x^{*}, x_{n+1}, T x^{*}\right), G\left(x_{n}, x^{*}, x^{*}\right), \\
& G\left(x_{n}, x_{n+1}, x_{n+1}\right), G\left(x^{*}, T x^{*}, T x^{*}\right), G\left(x^{*}, T x^{*}, T x^{*}\right), \\
& \left.G\left(x^{*}, x_{n+1}, x_{n+1}\right), G\left(x_{n}, T x^{*}, T x^{*}\right), G\left(x^{*}, T x^{*}, T x^{*}\right)\right\} .
\end{aligned}
$$

Letting $n \rightarrow \infty$ in (22) and using the fact that the metric $G$ is continuous, we get that either

$$
G\left(x^{*}, T x^{*}, T x^{*}\right) \leq k G\left(x^{*}, T x^{*}, T x^{*}\right)
$$

or

$$
G\left(x^{*}, T x^{*}, T x^{*}\right) \leq k G\left(x^{*}, x^{*}, T x^{*}\right) \leq k\left[2 G\left(x^{*}, T x^{*}, T x^{*}\right)\right]
$$

by the rectangular property (G5). Since $0 \leq k<\frac{1}{2}$, the inequalities above yield contradictions. Hence we have $G\left(x^{*}, T x^{*}, T x^{*}\right)=0$, that is, $x^{*}=T x^{*}$.

Finally, we shall show that $x^{*}$ is the unique fixed point of $T$. Suppose that contrary to our claim, there exists another common fixed point $t^{*} \in X$ with $t^{*} \neq x^{*}$. From (4) we have

$$
G\left(t^{*}, t^{*}, x^{*}\right)=G\left(T t^{*}, T t^{*}, T x^{*}\right) \leq k M\left(t^{*}, t^{*}, x^{*}\right),
$$

where

$$
M\left(t^{*}, t^{*}, x^{*}\right)=\max \left\{G\left(t^{*}, t^{*}, x^{*}\right), G\left(t^{*}, x^{*}, x^{*}\right)\right\} .
$$

Hence, the inequality (25) is equal to either

$$
G\left(t^{*}, t^{*}, x^{*}\right) \leq k G\left(t^{*}, t^{*}, x^{*}\right)
$$

or

$$
G\left(t^{*}, t^{*}, x^{*}\right) \leq k G\left(t^{*}, x^{*}, x^{*}\right) \leq 2 k G\left(t^{*}, t^{*}, x^{*}\right) .
$$

Since $0 \leq k<\frac{1}{2}$, the expressions (26) and (27) yield contradictions. Thus, $x^{*}$ is the unique fixed point of $T$. 
In Theorem 3.1, the interval of constant of the contractive condition can be extended to the interval $[0,1)$ by eliminating the same terms. Since the proof is the mimic of Theorem 3.1, we omit it.

Theorem 3.2 Let $(X, G)$ be a G-metric space. Let $T: X \rightarrow X$ be a mapping such that

$$
G(T x, T y, T z) \leq k M(x, y, z)
$$

for all $x, y, z$, where $k \in[0,1)$ and

$$
\begin{aligned}
M(x, y, z)= & \max \left\{G(x, T x, y), G\left(y, T^{2} x, T y\right), G\left(T x, T^{2} x, T y\right), G(x, T x, z),\right. \\
& G\left(z, T^{2} x, T z\right), G\left(T x, T^{2} x, T z\right), G(x, y, z), G(x, T x, T x), G(y, T y, T y), \\
& G(z, T z, T z), G(z, T x, T x), G(y, T z, T z)\} .
\end{aligned}
$$

Then there is a unique $x \in X$ such that $T x=x$.

Remark 3.1 Theorem 2.1-Theorem 2.6 are the consequences of Theorem 3.1 and Theorem 3.2.

Inspired by Theorem 2.8, we state the following theorem for which the methods in [37, 38] are not applicable.

Theorem 3.3 Let $(X, G)$ be a complete G-metric space and let $T: X \rightarrow X$ be a given mapping satisfying

$$
G\left(T x, T^{2} x, T y\right) \leq G(x, T x, y)-\varphi(G(x, T x, y))
$$

for all $x, y \in X$, where $\varphi:[0, \infty) \rightarrow[0, \infty)$ is continuous with $\varphi^{-1}(\{0\})=0$. Then there is a unique $x \in X$ such that $T x=x$.

Proof We first show that if the fixed point of the operator $T$ exists, then it is unique. Suppose, on the contrary, that $z, w$ are two fixed points of $T$ such that $z \neq w$. Hence, $G(z, z, w) \neq 0$. By (29), we have

$$
G\left(T z, T^{2} z, T w\right) \leq G(z, T z, w)-\varphi(G(z, T z, w))
$$

which is equivalent to

$$
G(z, z, w) \leq G(z, z, w)-\varphi(G(z, z, w))
$$

a contradiction. Hence, $T$ has a unique fixed point.

Let $x_{0} \in X$. We define a sequence $\left\{x_{n}\right\}$ in the following way:

$$
x_{n+1}=T x_{n}, \quad n \in \mathbb{N} .
$$


If $x_{n_{0}}=x_{n_{0}+1}$ for some $n_{0} \in \mathbb{N}$, then we get the desired result. From now on, we assume that $x_{n}=x_{n+1}$ for some $n \in \mathbb{N}$. Taking $x=x_{n}, z=y=x_{n+1}$ in (29), we find

$$
\begin{aligned}
G\left(x_{n+1}, x_{n+2}, x_{n+2}\right) & =G\left(T x_{n}, T x_{n+1}, T x_{n+1}\right) \\
& \leq G\left(x_{n}, T x_{n}, x_{n+1}\right)-\varphi\left(G\left(x_{n}, T x_{n}, x_{n+1}\right)\right) \\
& =G\left(x_{n}, x_{n+1}, x_{n+1}\right)-\varphi\left(G\left(x_{n}, x_{n+1}, x_{n+1}\right)\right) \\
& <G\left(x_{n}, x_{n+1}, x_{n+1}\right) .
\end{aligned}
$$

Hence, $\left\{G\left(x_{n}, x_{n+1}, x_{n+1}\right)\right\}$ is a positive decreasing sequence. Thus, the sequence $\left\{G\left(x_{n}, x_{n+1}\right.\right.$, $\left.\left.x_{n+1}\right)\right\}$ converges to $L \geq 0$. We shall show that $L=0$. Suppose, on the contrary, that $L>0$. Letting $n \rightarrow \infty$ in (33), we find that

$$
L \leq L-\varphi(L)
$$

It is a contradiction. Hence, we conclude that

$$
\lim _{n \rightarrow \infty}\left\{G\left(x_{n}, x_{n+1}, x_{n+1}\right)\right\}=0 .
$$

Moreover, by Lemma 2.1, we derive that

$$
\lim _{n \rightarrow \infty}\left\{G\left(x_{n}, x_{n}, x_{n+1}\right)\right\}=0 .
$$

Now, we demonstrate that the sequence $\left\{x_{n}\right\}$ is G-Cauchy. Suppose that $\left\{x_{n}\right\}$ is not GCauchy. So, there exists $\varepsilon>0$ and subsequences $\left\{x_{n(k)}\right\}$ and $\left\{x_{m(k)}\right\}$ of $\left\{x_{n}\right\}$ with $n(k)>$ $m(k)>k$ such that

$$
G\left(x_{n(k)}, x_{m(k)}, x_{m(k)}\right) \geq \varepsilon \quad \text { for all } k \in \mathbb{N} \text {. }
$$

Furthermore, corresponding to $m(k)$, one can choose $n(k)$ such that it is the smallest integer with $n(k)>m(k)$ satisfying (37). Thus, we have

$$
G\left(x_{n(k)-1}, x_{m(k)}, x_{m(k)}\right)<\varepsilon \quad \text { for all } k \in \mathbb{N} \text {. }
$$

By the triangle inequality, we get

$$
\varepsilon \leq G\left(x_{n(k)}, x_{m(k)}, x_{m(k)}\right) \leq G\left(x_{n(k)}, x_{n(k)-1}, x_{n(k)-1}\right)+G\left(x_{n(k)-1}, x_{m(k)}, x_{m(k)}\right) .
$$

Letting $k \rightarrow \infty$ in the expression (39) and keeping (36) in mind, we find

$$
\lim _{n \rightarrow \infty} G\left(x_{n(k)}, x_{m(k)}, x_{m(k)}\right)=\varepsilon .
$$

On the other hand, we have

$$
\begin{aligned}
G\left(x_{n(k)+1}, x_{m(k)+1}, x_{m(k)+1}\right) \leq & G\left(x_{n(k)+1}, x_{n(k)}, x_{n(k)}\right) \\
& +G\left(x_{n(k)}, x_{m(k)}, x_{m(k)}\right)+G\left(x_{m(k)}, x_{m(k)+1}, x_{m(k)+1}\right)
\end{aligned}
$$


and

$$
\begin{aligned}
G\left(x_{n(k)}, x_{m(k)}, x_{m(k)}\right) \leq & G\left(x_{n(k)}, x_{n(k)+1}, x_{n(k)+1}\right) \\
& +G\left(x_{n(k)+1}, x_{m(k)+1}, x_{m(k)+1}\right)+G\left(x_{m(k)+1}, x_{m(k)}, x_{m(k)}\right) .
\end{aligned}
$$

Letting $k \rightarrow \infty$ in the expression (41)-(42) and regarding (35), (36) and (40), we derive

$$
\lim _{n \rightarrow \infty} G\left(x_{n(k)+1}, x_{m(k)+1}, x_{m(k)+1}\right)=\varepsilon
$$

Further, we have

$$
\begin{aligned}
G\left(x_{n(k)}, x_{m(k)}, x_{m(k)}\right) & \leq G\left(x_{n(k)}, x_{m(k)}, x_{m(k)+1}\right) \\
& \leq G\left(x_{n(k)}, x_{m(k)}, x_{m(k)}\right)+G\left(x_{m(k)}, x_{m(k)}, x_{m(k)+1}\right)
\end{aligned}
$$

by (G3) and the triangle inequality. Letting $k \rightarrow \infty$ in (44) and using (35), (36) and (40), we conclude that

$$
\lim _{n \rightarrow \infty} G\left(x_{n(k)}, x_{m(k)}, x_{m(k)+1}\right)=\varepsilon
$$

Analogously, we have

$$
\begin{aligned}
G\left(x_{n(k)+1}, x_{m(k)+1}, x_{m(k)+1}\right) & \leq G\left(x_{n(k)+1}, x_{m(k)+2}, x_{m(k)+1}\right) \\
& \leq G\left(x_{n(k)+1}, x_{m(k)+1}, x_{m(k)+1}\right)+G\left(x_{m(k)+1}, x_{m(k)+2}, x_{m(k)+1}\right)
\end{aligned}
$$

by (G3) and the triangle inequality. Letting $k \rightarrow \infty$ in (44) and using (35), (36) and (43), we conclude that

$$
\lim _{n \rightarrow \infty} G\left(x_{n(k)+1}, x_{m(k)+2}, x_{m(k)+1}\right)=\varepsilon
$$

Due to (33) and regarding (G4), we obtain

$$
\begin{aligned}
G\left(T x_{m(k)}, T^{2} x_{m(k)}, T x_{n(k)}\right) & =G\left(x_{m(k)+1}, x_{m(k)+2}, x_{n(k)+1}\right) \\
& =G\left(x_{n(k)+1}, x_{m(k)+2}, x_{m(k)+1}\right) \\
& \leq G\left(x_{n(k)}, x_{m(k)}, x_{m(k)+1}\right)-\varphi\left(G\left(x_{n(k)}, x_{m(k)}, x_{m(k)+1}\right)\right)
\end{aligned}
$$

for all $k \in \mathbb{N}$. Letting $k \rightarrow \infty$ in the inequality (48) and keeping (45) and (47) in mind, we get

$$
\varepsilon \leq \varepsilon-\phi(\varepsilon)
$$

a contradiction. Hence, $\left\{x_{n}\right\}$ is a $G$-Cauchy sequence. Since $(X, G)$ is $G$-complete, there is $z \in X$ such that $x_{n} \rightarrow z$. 
We claim that $T z=z$. From (33), we have

$$
\begin{aligned}
G\left(x_{n+1}, x_{n+2}, T z\right) & =G\left(T x_{n}, T^{2} x_{n}, T z\right) \\
& \leq G\left(x_{n}, T x_{n}, z\right)-\varphi\left(G\left(x_{n}, T x_{n}, z\right)\right) \\
& =G\left(x_{n}, x_{n+1}, z\right)-\varphi\left(G\left(x_{n}, x_{n+1}, z\right)\right) .
\end{aligned}
$$

Letting $k \rightarrow \infty$ in (50), regarding the continuity of $G$, we get that

$$
G(z, z, T z) \leq G(z, z, z)-\varphi(G(z, z, z))=0 .
$$

Hence $G(z, z, T z)=0$, that is, $T z=z$.

Remark 3.2 Let $X$ be a nonempty set. We define functions $p, d: X \times X \rightarrow[0, \infty)$ in the following way:

$$
d(x, y)=\left(y, T^{2} x, T y\right) \quad \text { and } \quad p(x, y)=G\left(T x, T^{2} x, T y\right)
$$

for all $x, y \in X$. It is easy to see that both mappings $p$ and $q$ do not satisfy the conditions of Definition 2.6. Hence, Theorem 3.1 and Theorem 3.3 cannot be characterized in the context of quasi-metric as it is suggested in $[37,38]$.

Example 3.1 Let $X=[0, \infty), G: X \times X \times X \rightarrow \mathbb{R}$ be defined by

$$
G(x, y, z)= \begin{cases}0 & \text { if } x=y=z, \\ \max \{x, y, z\} & \text { otherwise }\end{cases}
$$

Then $(X, G)$ is a $G$-complete $G$-metric space. Let $T: X \rightarrow X$ be defined by

$$
T x= \begin{cases}\frac{1}{4} x & \text { if } 0 \leq x<1 / 3 \\ \frac{1}{8} x^{4} & \text { if } 1 / 3 \leq x \leq 1\end{cases}
$$

and $\varphi(t)=\frac{3}{4} t$ for all $t \in[0,+\infty)$.

Proof For the proof the Example 3.1, we examine the following cases:

- Let $0 \leq x, y<1 / 3$. Then

$$
\begin{aligned}
G\left(T x, T^{2} x, T y\right) & =\max \left\{\frac{1}{4} x, \frac{1}{16} x, \frac{1}{4} y\right\} \leq \frac{1}{4} \max \left\{x, \frac{1}{4} x, y\right\} \\
& =G(x, T x, y)-\varphi(G(x, T x, y)) .
\end{aligned}
$$

- Let $1 / 3 \leq x, y<1$. Then

$$
\begin{aligned}
G\left(T x, T^{2} x, T y\right) & =\max \left\{\frac{1}{8} x^{4}, \frac{1}{64} x^{16}, \frac{1}{8} y^{4}\right\} \leq \frac{1}{4} \max \left\{x, \frac{1}{8} x^{4}, y\right\} \\
& =G(x, T x, y)-\varphi(G(x, T x, y)) .
\end{aligned}
$$


- Let $0 \leq x<1 / 3 \leq y<1$. Then

$$
\begin{aligned}
G\left(T x, T^{2} x, T y\right) & =\max \left\{\frac{1}{4} x, \frac{1}{16} x, \frac{1}{8} y^{4}\right\} \leq \frac{1}{4} \max \left\{x, \frac{1}{4} x, y\right\} \\
& =G(x, T x, y)-\varphi(G(x, T x, y)) .
\end{aligned}
$$

- Let $0 \leq y<1 / 3 \leq x<1$. Then

$$
\begin{aligned}
G\left(T x, T^{2} x, T y\right) & =\max \left\{\frac{1}{8} x^{4}, \frac{1}{64} x^{16}, \frac{1}{4} y\right\} \leq \frac{1}{4} \max \left\{x, \frac{1}{8} x^{4}, y\right\} \\
& =G(x, T x, y)-\varphi(G(x, T x, y)) .
\end{aligned}
$$

Then

$$
G\left(T x, T^{2} x, T y\right) \leq G(x, T x, y)-\varphi(G(x, T x, y)) .
$$

Then the conditions of Theorem 3.3 hold and $T$ has a unique fixed point. Notice that $(0,0,0)$ is the desired fixed point of $T$.

\section{Competing interests}

The authors declare that they have no competing interests.

\section{Authors' contributions}

All authors read and approved the final manuscript.

\section{Author details}

${ }^{1}$ Department of Mathematics, Atilim University, İncek, Ankara 06836, Turkey. ${ }^{2}$ Department of Mathematics, Texas A\&M University-Kingsville, Rhode Hall 217B, MSC 172, Kingsville, Texas 78363-8202, USA. ${ }^{3}$ Department of Mathematics, Faculty of Science, King Abdulaziz University, Jeddah, 21589, Saudi Arabia.

\section{Acknowledgements}

The authors express their gratitude to the anonymous referees for constructive and useful remarks, comments and suggestions. The first author thank to student Peyman Salimi for his help for Example 3.1.

Received: 26 February 2013 Accepted: 28 May 2013 Published: 17 June 2013

\section{References}

1. Mustafa, Z, Sims, B: A new approach to generalized metric spaces. J. Nonlinear Convex Anal. 7(2), $289-297$ (2006)

2. Banach, S: Sur les opérations dans les ensembles abstraits et leur application aux équations intégrales. Fundam. Math. 3, 133-181 (1922)

3. Abbas, M, Sintunavarat, W, Kumam, P: Coupled fixed point of generalized contractive mappings on partially ordered G-metric spaces. Fixed Point Theory Appl. 2012, Article ID 31 (2012)

4. Abbas, M, Nazir, T, Vetro, P: Common fixed point results for three maps in G-metric spaces. Filomat 25(4), 1-17 (2011)

5. Agarwal, R, Karapınar, E: Remarks on some coupled fixed point theorems in G-metric spaces. Fixed Point Theory Appl. 2013, Article ID 2 (2013)

6. Aydi, H, Shatanawi, W, Vetro, C: On generalized weak G-contraction mapping in G-metric spaces. Comput. Math. Appl. 62, 4223-4229 (2011)

7. Aydi, H, Karapinar, E, Shatnawi, W: Tripled fixed point results in generalized metric spaces. J. Appl. Math. 2012, Article ID 314279 (2012)

8. Aydi, H, Karapinar, E, Mustafa, Z: On common fixed points in G-metric spaces using (E.A) property. Comput. Math. Appl. 64(6), 1944-1956 (2012)

9. Aydi, H, Postolache, M, Shatanawi, W: Coupled fixed point results for $(\psi, \phi)$-weakly contractive mappings in ordered G-metric spaces. Comput. Math. Appl. 63(1), 298-309 (2012)

10. Aydi, H, Karapınar, E, Shatanawi, W: Tripled fixed point results in generalized metric spaces. J. Appl. Math. 2012, Article ID 314279 (2012)

11. Aydi, H, Damjanović, B, Samet, B, Shatanawi, W: Coupled fixed point theorems for nonlinear contractions in partially ordered G-metric spaces. Math. Comput. Model. 54, 2443-2450 (2011)

12. Berinde, $\mathrm{V}$ : Generalized coupled fixed point theorems for mixed monotone mappings in partially ordered metric spaces. Nonlinear Anal. 74, 7347-7355 (2011) 
13. Berinde, V: Coupled fixed point theorems for $\Phi$-contractive mixed monotone mappings in partially ordered metric spaces. Nonlinear Anal. 75, 3218-3228 (2012)

14. Berinde, $\mathrm{V}$ : Coupled coincidence point theorems for mixed monotone nonlinear operators. Comput. Math. Appl. (2012). doi:10.1016/j.camwa.2012.02.012

15. Cho, YJ, Rhoades, BE, Saadati, R, Samet, B, Shatanawi, W: Nonlinear coupled fixed point theorems in ordered generalized metric spaces with integral type. Fixed Point Theory Appl. 2012, Article ID 8 (2012)

16. Choudhury, BS, Kundu, A: A coupled coincidence point result in partially ordered metric spaces for compatible mappings. Nonlinear Anal. 73, 2524-2531 (2010)

17. Choudhury, BS, Maity, P: Coupled fixed point results in generalized metric spaces. Math. Comput. Model. 54, 73-79 (2011)

18. Ćirić, L: A generalization of Banach's contraction principle. Proc. Am. Math. Soc. 45(2), 267-273 (1974)

19. Ćirić, L, Agarwal, RP, Samet, B: Mixed monotone-generalized contractions in partially ordered probabilistic metric spaces. Fixed Point Theory Appl. 2011, Article ID 56 (2011)

20. Ding, H-S, Karapınar, E: A note on some coupled fixed point theorems on G-metric space. J. Inequal. Appl. 2012 Article ID 170 (2012)

21. Mustafa, Z, Aydi, H, Karapınar, E: On common fixed points in image-metric spaces using (E.A) property. Comput. Math. Appl. 64(6), 1944-1956 (2012)

22. Mustafa, Z: A new structure for generalized metric spaces with applications to fixed point theory. Ph.D. thesis, The University of Newcastle, Australia (2005)

23. Mustafa, Z, Obiedat, H, Awawdeh, F: Some fixed point theorem for mapping on complete G-metric spaces. Fixed Point Theory Appl. 2008, Article ID 189870 (2008)

24. Mustafa, Z, Khandaqji, M, Shatanawi, W: Fixed point results on complete G-metric spaces. Studia Sci. Math. Hung. 48, 304-319 (2011)

25. Mustafa, Z, Sims, B: Fixed point theorems for contractive mappings in complete G-metric spaces. Fixed Point Theory Appl. 2009, Article ID 917175 (2009)

26. Mustafa, Z, Shatanawi, W, Bataineh, M: Existence of fixed point results in G-metric spaces. Int. J. Math. Math. Sci. 2009, Article ID 283028 (2009)

27. Mustafa, Z, Obiedat, H: A fixed point theorem of Reich in G-metric spaces. CUBO 12(1), 83-93 (2010)

28. Nashine, HK: Coupled common fixed point results in ordered G-metric spaces. J. Nonlinear Sci. Appl. 1, 1-13 (2012)

29. Rasouli, SH, Bahrampour, M: A remark on the coupled fixed point theorems for mixed monotone operators in partially ordered metric spaces. J. Math. Comput Sci. 3(2), 246-261 (2011)

30. Samet, B: Coupled fixed point theorems for a generalized Meir-Keeler contraction in partially ordered metric spaces. Nonlinear Anal. 74, 4508-4517 (2010)

31. Shatanawi, W: Coupled fixed point theorems in generalized metric spaces. Hacet. J. Math. Stat. 40(3), $441-447$ (2011)

32. Shatanawi, W: Fixed point theory for contractive mappings satisfying $\Phi$-maps in $G$-metric spaces. Fixed Point Theory Appl. 2010, Article ID 181650 (2010)

33. Shatanawi, W: Some fixed point theorems in ordered G-metric spaces and applications. Abstr. Appl. Anal. 2011, Article ID 126205 (2011)

34. Shatanawi, W: Coupled fixed point theorems in generalized metric spaces. Hacet. J. Math. Stat. 40(3), $441-447$ (2011)

35. Shatanawi, W, Abbas, M, Nazir, T: Common coupled coincidence and coupled fixed point results in two generalized metric spaces. Fixed Point Theory Appl. 2011, Article ID 80 (2011)

36. Tahat, N, Aydi, H, Karapınar, E, Shatanawi, W: Common fixed points for single-valued and multi-valued maps satisfying a generalized contraction in G-metric spaces. Fixed Point Theory Appl. 2012, Article ID 48 (2012)

37. Samet, B, Vetro, C, Vetro, F: Remarks on G-metric spaces. Int. J. Anal. 2013, Article ID 917158 (2013)

38. Jleli, M, Samet, B: Remarks on G-metric spaces and fixed point theorems. Fixed Point Theory Appl. 2012, Article ID 210 (2012)

doi:10.1186/1687-1812-2013-154

Cite this article as: Karapınar and Agarwal: Further fixed point results on G-metric spaces. Fixed Point Theory and Applications 2013 2013:154

\section{Submit your manuscript to a SpringerOpen ${ }^{\circ}$ journal and benefit from:}

- Convenient online submission

- Rigorous peer review

- Immediate publication on acceptance

- Open access: articles freely available online

- High visibility within the field

- Retaining the copyright to your article 